\section{Resolution Test}

Checkerboard

Hit Quality

$200 \mathrm{~km}$ Wide Structure to $330 \mathrm{~km}$

$200 \mathrm{~km}$ Wide Structure to $565 \mathrm{~km}$

$100 \mathrm{~km}$ Wide Structure to $330 \mathrm{~km}$

\section{Depth}

$\begin{array}{llll}60 \mathrm{~km} & 165 \mathrm{~km} & 285 \mathrm{~km} & 420 \mathrm{~km} \\ 90 \mathrm{~km} & 205 \mathrm{~km} & 330 \mathrm{~km} & 465 \mathrm{~km} \\ 125 \mathrm{~km} & 245 \mathrm{~km} & 375 \mathrm{~km} & \end{array}$

Figure 5. Interactive. Map views of a checkerboard test, resolution of synthetic input structures, and "hit quality." Radio buttons allow you to interactively select the resolution test type and the depth slice. The standard checkerboard test is of cubes $200 \mathrm{~km}$ per side and $+10 \%$ or $-10 \%$ the reference S-wave speed at each depth of AK135. The synthetic input structures $(+10 \%$ Vs of the reference model, AK135) simulate vertical slabs of high-speed material with widths of either $200 \mathrm{~km}$ or $100 \mathrm{~km}$ that extend from $60 \mathrm{~km}$ to $330 \mathrm{~km}$ (slab to $330 \mathrm{~km}$ ) and from $60 \mathrm{~km}$ to $565 \mathrm{~km}$ (slab to $565 \mathrm{~km}$ ). Synhtic travel thes were calculated by tracing rays through the synetic structures using the same station and event distribution as observed. In the case of the synthetic structure tests simulating slabs, random noise of root mean square $=1.35 \mathrm{~s}$ was added to the synthetic travel times. The synthetic travel times are then inverted for speed perturbation using the same method as with the measured arrval thes. The hit quality parameter demonstrates ray coverage, with cooler colors representing better resolved regions. To interact with Figure 5 for the PDF version orthis paper, openthe PDFin Adose Acrobat or A download a PDF of Figure 5. 